GA-A23990

\title{
ROLE OF NEUTRALS IN CORE FUELING AND PEDESTAL STRUCTURE IN H-MODE DIII-D DISCHARGES
}

\author{
by \\ N.S. WOLF, T.W. PETRIE, G.D. PORTER, T.D. ROGNLIEN, \\ R.J. GROEBNER, and M.A. MAKOWSKI
}




\section{DISCLAIMER}

This report was prepared as an account of work sponsored by an agency of the United States Government. Neither the United States Government nor any agency thereof, nor any of their employees, makes any warranty, express or implied, or assumes any legal liability or responsibility for the accuracy, completeness, or usefulness of any information, apparatus, product, or process disclosed, or represents that its use would not infringe privately owned rights. Reference herein to any specific commercial product, process, or service by trade name, trademark, manufacturer, or otherwise, does not necessarily constitute or imply its endorsement, recommendation, or favoring by the United States Government or any agency thereof. The views and opinions of authors expressed herein do not necessarily state or reflect those of the United States Government or any agency thereof. 
GA-A23990

\title{
ROLE OF NEUTRALS IN CORE FUELING AND PEDESTAL STRUCTURE IN H-MODE DIII-D DISCHARGES
}

\author{
by \\ N.S. WOLF, ${ }^{\dagger}$ T.W. PETRIE, G.D. PORTER, ${ }^{\dagger}$ T.D. ROGNLIEN, ${ }^{\dagger}$ \\ R.J. GROEBNER, and M.A. MAKOWSKI† \\ † Lawrence Livermore National Laboratory
}

This is a preprint of a paper presented at the 15th International Conference on Plasma Surface Interactions in Controlled Fusion Devices, May 27-31, 2002, in Gifu, Japan, and to be published in the Proceedings.

\author{
Work supported by \\ the U.S. Department of Energy \\ under Contracts W-7405-ENG-48 and DE-AC03-99ER54463
}

GA PROJECT 30033

OCTOBER 2002 


\begin{abstract}
The 2-D fluid code UEDGE was used to analyze DIII-D experiments to determine the role of neutrals in core fueling, core impurities, and also the $\mathrm{H}$-mode pedestal structure. We compared the effects of divertor closure on the fueling rate and impurity density of high-triangularity, $\mathrm{H}$-mode plasmas. UEDGE simulations indicate that the decrease in both deuterium core fueling $(\approx 15 \%-20 \%)$ and core carbon density $(\approx 15 \%-30 \%)$ with the closed divertor compared to the open divertor configuration is due to greater divertor screening of neutrals. We also compared UEDGE results with a simple analytic model of the $\mathrm{H}$-mode pedestal structure [M.A. Mahdavi, et al., Nucl. Fusion 42 (2002) 52.]. The model predicts both the width and gradient of the transport barrier in $n_{\mathrm{e}}$ as a function of the pedestal density. The more sophisticated UEDGE simulations of $\mathrm{H}$-mode discharges corroborate the simple analytic model, which is consistent with the hypothesis that fueling processes play a role in $\mathrm{H}$-mode transport barrier formation.
\end{abstract}

Keywords: UEDGE, simulations, fueling, core carbon, pedestal width, pedestal gradient 


\section{DIVERTOR CLOSURE AND FUELING OF THE CORE PLASMA}

In low density discharges both modeling and experimental results from DIII-D have demonstrated the effectiveness of the closed divertor in preventing recycled neutrals from returning to the core $[1,2]$. This paper extends these results to higher core plasma density; core fueling rates and impurity content are calculated. The advantages of trapping neutrals in a closed divertor by comparing fueling rates and impurity content in the plasma core for higher densities are explored. Since high-triangularity plasmas in the open (lower) divertor cannot be actively pumped, we limit this study to unpumped, ELMing H-mode discharges. The single-null plasmas considered in this study were characterized by: $\mathrm{I}_{\mathrm{P}}=1.37 \mathrm{MA}, q_{95}=4.1, \mathrm{P}_{\mathrm{INPUT}}=3.0-7.5 \mathrm{MW}$, $\mathrm{n}_{\mathrm{e}} / \mathrm{n}_{\mathrm{GW}} \approx 0.6-0.8$, and triangularity at the $\mathrm{X}$-point $\delta=0.74$.

Experiments showed that core fueling was $\sim 10 \%-20 \%$ lower in the closed diverted plasmas than in the open diverted plasmas, given the same density (e.g., $n_{\mathrm{e}} / \mathrm{n}_{\mathrm{GW}} \geq 0.7$ ), gas puff rate, energy confinement time, and power level [3]. To help analyze these experiments, the 2-D fluid plasma code UEDGE [4] was used to model two similar high density "attached" discharges under open and closed divertor geometry. UEDGE solves equations for ion continuity, energy and momentum on a 2-D domain, simulating the discharge from the $96 \%$ flux surface to the limiter surface in the radial direction and from plate to plate in the poloidal direction. Constant radial particle $\left(0.075 \mathrm{~m}^{2} / \mathrm{s}\right)$ and energy $\left(0.3 \mathrm{~m}^{2} / \mathrm{s}\right)$ diffusivities (to model turbulence) are used. UEDGE results indicate that the core deuterium fueling rate should be $\approx 20 \%$ lower in the closed divertor case in comparison with the corresponding open divertor case in agreement with the data.

This result is consistent with an independent approach that is based on the evolution of the radial profiles of the core density and temperature [5]. Our UEDGE analysis shows the recycling current in the closed divertor case was roughly twice that of the open divertor case. However, the contribution of this higher recycling current was offset by greater divertor screening, and thus a lower probability ( $\approx 40 \%$ that of the open divertor case) of these neutrals returning to fuel the core. The net fueling rate of the core, which is the product of these two factors, is about $20 \%$ lower in the closed divertor case. UEDGE results indicate that the electron temperature was high enough to efficiently ionize recycling neutrals between the $\mathrm{X}$-point and the divertor target in the closed divertor case, showing the effectiveness of its divertor screening of neutrals, as shown in Fig. 1. UEDGE analysis also shows that the largest neutral fueling region for both open and closed divertor cases is localized at or slightly upstream from the X-point on the inboard side (Fig. 2). 

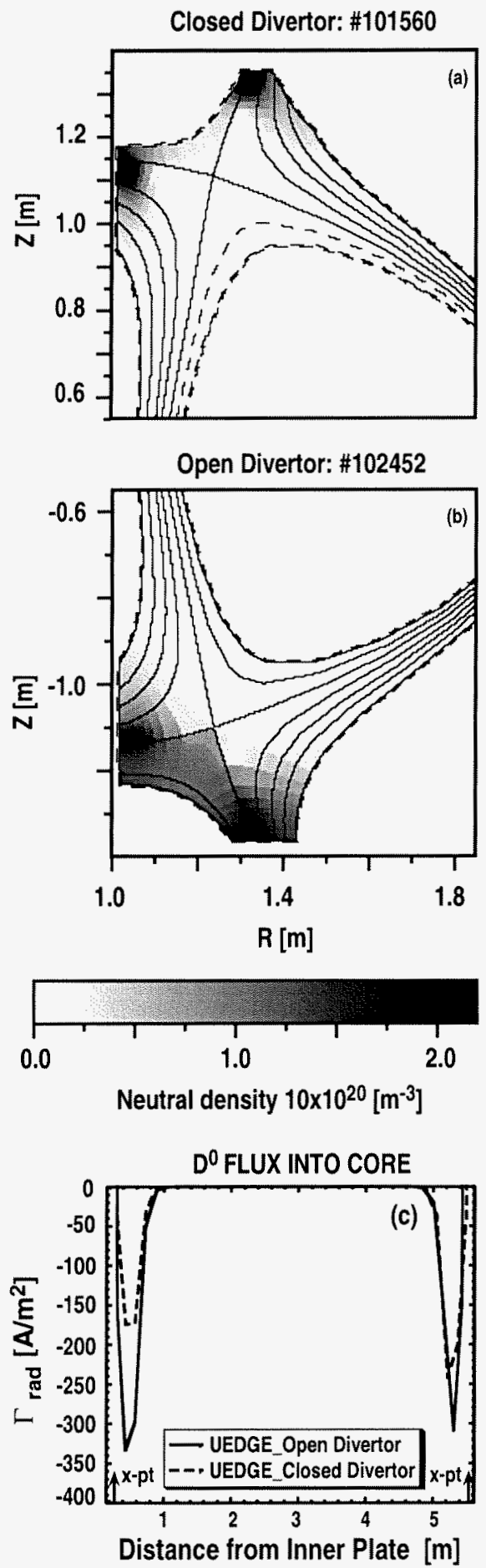

Fig. 1. Restriction of neutrals to the regions near to the closed divertor plates (a) reduces $\mathrm{D}^{\circ}$ around the $\mathrm{X}$-point compared to the open divertor (b). The radial flux of neutral deuterium (c) is shown as a function of poloidal distance along the separatrix from the inner strike point (ISP) and indicates the larger the radial $D^{\circ}$ flux into the core with the open divertor.

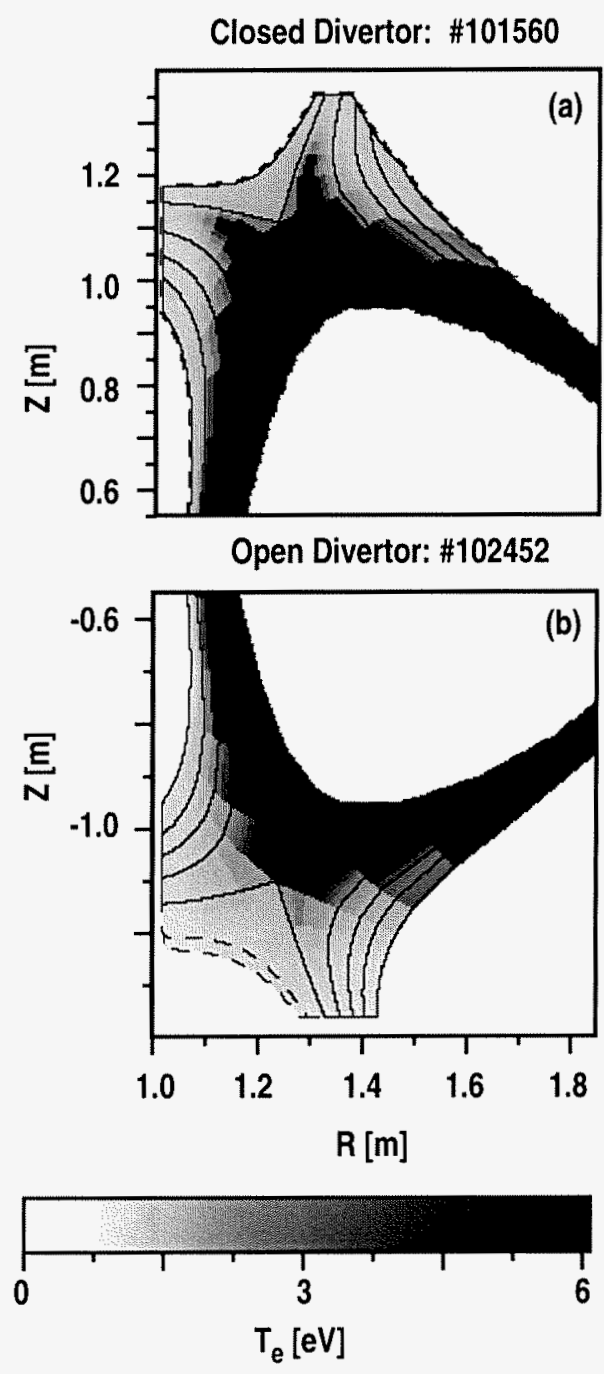

Fig. 2. The 2-D plot of $\mathrm{T}_{\mathrm{e}}$ shows that the $\mathrm{Te}>4 \mathrm{eV}$ region extends closer to the closed divertor plates (c) than the open divertor (b), providing greater screening of neutrals returning to the core. 


\section{DIVERTOR CLOSURE AND CORE CARBON DENSITY}

For comparable density and power input, the carbon density in the core plasma was found to be $\approx 15 \%-30 \%$ lower in closed divertor cases than in open divertor cases, in the parameter range $\mathrm{n}_{\mathrm{e}} / \mathrm{n}_{\mathrm{GW}} \approx 0.6-0.7$ and $\mathrm{P}_{\mathrm{INPUT}}=3.0-7.5 \mathrm{MW}$. Carbon content in the plasma core for either $\mathrm{H}$-mode case, however, was low (i.e., $\mathrm{Z}_{\mathrm{eff}} \leq 1.6$ ). UEDGE modeling indicates two reasons for the lower core carbon density with the closed divertor. First the restriction of neutrals in the closed divertor decreased the carbon sputtered from nearby walls, Fig. 2(a). Second that the two baffles of the closed divertor reduced the probability of scattered carbon impurity escaping the divertor, either through the private flux region toward the $\mathrm{X}$-point or out between the scrape-off layer and the vessel wall. The net result for the closed divertor case was lower carbon density near the $\mathrm{X}$-point and upstream along the separatrix. This, in turn, ultimately led to fewer carbon ions diffusing into the core. For example, Fig. 3 shows the radial flux of $\mathrm{C}^{4+}$ into the core of the open and closed divertor cases; $\mathrm{C}^{4+}$ was the main carbon ion along the separatrix flux surface, where $\mathrm{T}_{\mathrm{e}}$ $\approx 50-100 \mathrm{eV}$. Thus, the restricted range of

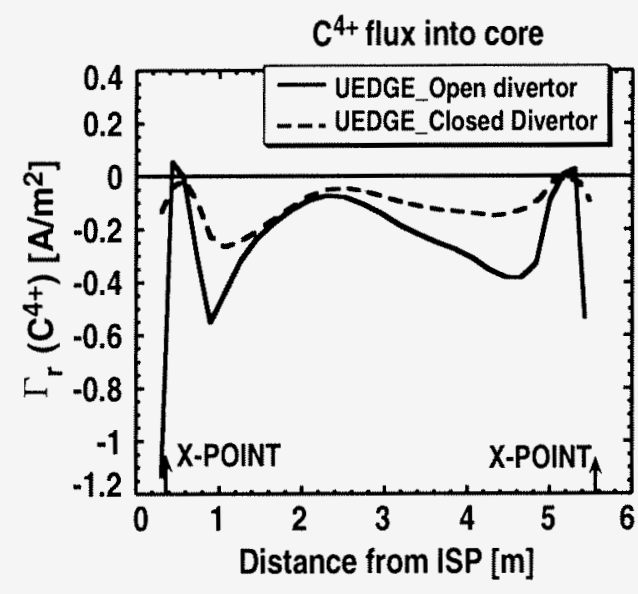

Fig. 3. The radial flux of $\mathrm{C}^{4+}$ is shown as a function of poloidal distance along the separatrix from the inner strike point (ISP) to the outer strike point for both open and closed divertor cases. UEDGE analysis shows the larger radial flux is $\mathrm{C}^{4+}$ into the core of the open divertor.

carbon impurities in the closed divertor region was a factor in lowering carbon ion flux along the scrape-off layer and reducing $\mathrm{C}^{4+}$ flux into the core above the $\mathrm{X}$-point. The source of carbon is assumed to be chemical and physical sputtering from the divertor plates and vessel walls. 


\section{NEUTRAL FUELING AND THE H-MODE PEDESTAL}

One uncertainty in the performance of next-step machines is the lack of detailed understanding of how the $\mathrm{H}$-mode pedestal will scale to these devices. Therefore, it is important to learn what physics determines the width of the $\mathrm{H}$-mode heat and particle barriers. Recent pedestal studies in the DIII-D tokamak find a strong correlation between the width of the $\mathrm{H}$-mode particle barrier $\mathrm{n}_{\mathrm{e} \text {,wid }}$ and the neutral penetration length $\lambda_{\mathrm{n}}$ [6]. These results are obtained by comparing experimental $n_{e}$ profiles to the predictions of a simple analytic model for the density profile $[7,8]$. The model, obtained from a self-consistent solution of the particle continuity equations for electrons and neutral deuterium atoms, predicts that $\lambda_{n}$ is determined self-consistently by particle transport fueling; it compares favorably with experimental results $[9,10]$. Bench-marking of this simple analytic slab model against the much more sophisticated fluid neutrals model in UEDGE yields similar results for the same model parameters. Within its range of validity (edge temperatures in the range $0.02-0.3 \mathrm{keV}$ ), the predictions of the analytic model are consistent in several ways with DIII-D measurements:

1. H-mode density profiles are predicted to have a hyperbolic tangent shape, as is observed.

2. The model predicts experimental widths of the $n_{e}$ profile and that the transport barrier width decreases as the density pedestal $n_{e}$,ped increases, observed experimentally over a wide range of $n_{e, p e d}$, Fig. 4(a), and corroborated by UEDGE simulations in Fig. 4(b). For the analytic model curve shown in Fig. 4(a), the numerical factor used to model the localization of the neutrals has been adjusted to give a good fit. This factor is in the range of

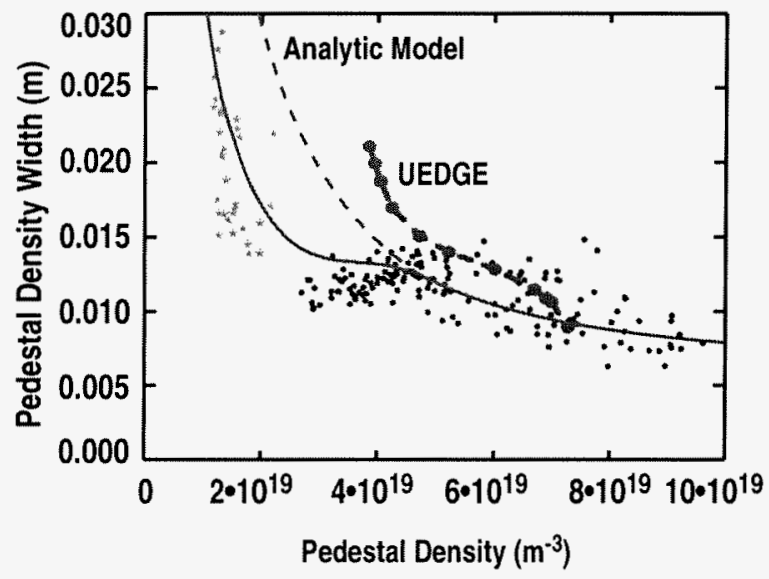

Fig. 4. Width of the density barrier decreases with increasing pedestal density. Note the numerical factor used to model the localization of the neutrals in the analytic model has been adjusted to give a good fit. UEDGE simulation corroborates both data and analytic model and has accurate divertor geometry for a typical $\mathrm{H}-$ mode discharge [fueling locations are an unadjusted outcome of the UEDGE simulation, seen in Fig. 1(c)]. localization factors obtained from modeling with the UEDGE code.

3. The model predicts that the maximum gradient of $n_{e}$ should be proportional to $\left(n_{e} \text {,ped }\right)^{2}$, consistent with experimental results, Fig. 5(a), and UEDGE simulations, as seen in Fig. 5(b). The analytic model curve was adjusted for neutral flux localization. 


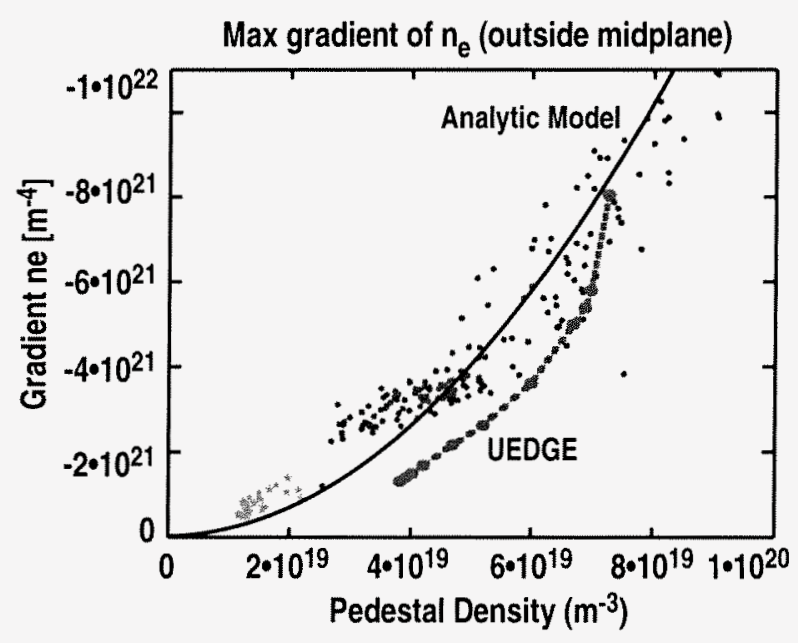

Fig. 5. Maximum density gradient of density barrier increases as the square of pedestal density. The numerical factor used to model the localization of the neutrals in the analytic model has been adjusted to give a good fit. UEDGE simulation of an $\mathrm{H}$-mode discharge shows a good fit to the data with fueling locations as in Fig. 1(c).

This correspondence of UEDGE and the analytic model results provides additional evidence that the width of the particle barrier depends on both plasma physics (particle and heat transport, because it produces the edge temperature profile) and atomic physics (neutral fueling). 


\section{SUMMARY AND CONCLUSIONS}

UEDGE modeling shows that the increased recycling current in the closed divertor was more than offset by its improved divertor screening of the recycled particles returning to the core. The geometric effect of the closed divertor appears to constrict neutrals to a region near the divertor plates, permitting a higher $\mathrm{T}_{\mathrm{e}}$ along the separatrix to effectively ionize neutrals returning to the core. This results in the observed, slightly lower deuterium core fueling rate for the closed divertor configuration. Also, the combination of decreased neutral density at the walls near the plates of the closed divertor and the geometric effect of the closed divertor appears responsible for the decreased core carbon density.

The analysis of DIII-D data is consistent with the analytic model hypothesis that the scale size of the H-mode particle barrier is determined not only by particle and heat transport, but also the location, energy, and flux of the fueling neutrals. UEDGE simulations of H-mode discharges in DIII-D tend to corroborate the simple analytic model (which is consistent with the idea that fueling processes play a role in $\mathrm{H}$-mode barrier formation). These new results further support the use of the analytic model to study trends in the plasma, despite the fact that the analytic model treats the neutral transport in a very simple way. 


\section{REFERENCES}

[1] S.L. Allen, et al., J. Nucl. Mater. 266-269 (1999) 168.

[2] G.D. Porter, et al., J. Nucl. Mater. 290-293 (2001) 692.

[3] T.W. Petrie, et al., Proc. 28th Euro. Conf. Contr. Fusion and Plasma Phys., Madiera, Portugal, (2001).

[4] T.D. Rognlien, et al., Contr. Plasma Phys. 34 (1994) 362.

[5] G.D. Porter and the DIII-D Team, Phys. Plasmas 5 (1998) 4311.

[6] M.A. Mahdavi, et al., Nucl. Fusion 42 (2002) 52.

[7] W. Englehardt, W. Fenenberg, J. Nucl. Mater. 76-77 (1978) 518.

[8] R.J. Groebner, T.H. Osborne, Phys. Plasmas 5 (1998) 1800.

[9] R.L. Boivin, et al., Phys. Plasmas 7 (2000) 1919.

[10] R.J. Groebner, et al., Phys. Plasmas 9 (2002) 2134. 


\section{ACKNOWLEDGMENT}

Work supported by U.S. Department of Energy under Contracts W-7405-ENG-48 and DE-AC03-99ER55463. 